\title{
CPFD simulation of a dual fluidized bed cold flow model
}

\author{
A. Lunzer ${ }^{1 *}$, S. Kraft' ${ }^{2,3}$, S. Müller ${ }^{2}$, H. Hofbauer ${ }^{2}$ \\ 1. Verto Engineering GmbH, Franz-Josefs Kai 53/13, 1010 Vienna, Austria \\ 2. TU Wien, Institute of Chemical, Environmental and Bioscience Engineering, \\ Getreidemarkt 9/166, 1060 Vienna, Austria \\ 3. Bioenergy 2020+ GmbH, Wiener Strasse 49, 7540 Güssing, Austria \\ *corresponding author, al@verto-engineering.com
}

\begin{abstract}
The present work was carried out to simulate a cold flow model of a biomass gasification plant. The fluid dynamical behavior depends heavily on the particles' properties like the particle size distribution (PSD). For the simulation an Eulerian-Lagrangian approach, in particular by the multi-phase particle in cell (MP-PIC) method, was used to simulate particles with a defined PSD. Therefore, Barracuda VR, a software tool with an implemented MP-PIC method specifically designed for CPFD (computational particle fluid dynamics) simulations, was the software of choice. The simulation results were verified with data of previously conducted experiments on a physical cold flow model. The cold flow model was operated with air and bronze particles. The simulations were conducted with different drag laws: an energyminimization multi-scale (EMMS) approach, a blended Wen-Yu and Ergun (WYE) drag law, and a drag law of Ganser. Furthermore, a focus was set onto the normal particle stress $\left(\mathrm{P}_{\mathrm{S}}\right.$ value variation), which is significant in close-packed regions, and the loop seals' fluidization rate was varied to influence the particle circulation rate. The settings of the simulation were optimized, flooding behavior did not occur in advanced simulations, and the simulations reached a stable steady state behavior. The Ganser drag law combined with an adjusted $\mathrm{P}_{\mathrm{S}}$ value with $\left(\mathrm{P}_{\mathrm{S}}=30 \mathrm{~Pa}\right)$ or without $\left(\mathrm{P}_{\mathrm{S}}=50 \mathrm{~Pa}\right)$ increased loop seal fluidization rates provided the best simulation results.
\end{abstract}

Keywords: Computational fluid dynamics, CPFD simulation, Cold flow model, Fluidized bed

\section{Introduction}

The demand for energy independency and renewable energy is increasing. Therefore, gasification technology is becoming more important. Dual fluid gasification is a promising technology to produce a product gas with a favorable gas composition which can be used for different products like synthetic natural gas and Fischer-Tropsch fuel.

Classical dual fluidized bed (DFB) gasification design in a bubbling bed without narrowings in the fuel reactor (FR) works well for conventional wood chips. There is an increased interest from industry to utilize alternative low-cost fuels, but those fuels can lead to higher tar concentrations in the product gas stream. The design with narrowings in the FR column increases the solid gas interaction above the bubbling bed. This measure led to lower tar contents in the product gas and overall increased product gas quality [1].

CFD (computational fluid dynamics) is a diverse tool for applications in research and industry. The application of CFD in gassolid multi-phase systems does face new challenges compared to traditional 
simulations solely focusing on fluids. Therefore, Barracuda VR, a software tool with an implemented MP-PIC (multi-phase particle in cell) method specifically designed for CPFD (computational particle fluid dynamics) simulation, was the software of choice. Because of the high particle number, the MP-PIC approach is an efficient option for larger plants and applications.

CPFD simulations turned out to be very useful for the investigation of mixing behavior of fuel and bed material in dual fluidized bed plants. Optimal contact between fuel and bed material ensures low tar content which is favorable for long and stable operation of such plants. Better mixing can be achieved with additional fluidization agent as Kuba et al. have shown [2]. With CPFD simulations the effect of such additional fuel nozzles can be investigated and their impact on overall mixing process in the gasification or fuel reactor.

In the present work the CPFD simulation of a cold flow model used for the up-scaling and dimensioning of a biomass gasification plant is the object of interest. Cold flow models are an important tool to study fluid dynamical behavior, scale up small plants, and offer the possibility to optimize and test the design of a plant on a small scale.

A verified CPFD model can reflect trends and predict the process in a plant with a certain degree of accuracy as well as allow fast testing of different plant modifications and optimization.

The goal of this work was to create a working CPFD model in Barracuda which predicts the behavior of the real cold flow model accurately and to gain deeper understanding of the behavior of the DFB gasification as well as simulations of fluidized beds.
The following questions were subject of interest:

- How do the different settings (e.g. (drag law, particle normal stress, etc.) in the CPFD software influence the particle behavior?

- What settings lead to the best performance at a specific operating point?

- Do the optimal settings predict reliable results at different operating points in the same system?

Barracuda has already been used for studies over a broad range of fluidization regimes, ranging from bubbling beds [3]-[5], spouting beds [6], risers [7]-[12], and full loop circulating fluidized beds (CFBs) [13] [18]. A brief literature review of already conducted simulations of CFBs is given subsequently.

A full loop CFB was simulated by Clark et al. [13] with a Wen and $\mathrm{Yu}$ drag law approach. The flow behavior matched well with video recordings. The pressure drops were reasonable accurate.

Wang et al. [14] simulated a CFB to investigate the influence of various modeling parameters. They simulated the CFB with the Wen-Yu drag model, which predicted the particle circulation rate best, two configurations of the WYE drag model, which predicted the total pressure drop best, and the Ganser drag model, which overestimated both the pressure drop and particle circulation rate.

Hamilton et al. [15] simulated a CFB using the Wen-Yu drag model, which overpredicted the drag force in the simulation, with higher circulation rates but with good predictions of the trend.

Adkins et al. [16] simulated a CFB with the WYE and a Parker drag model. The WYE 
drag model overestimated drag forces, while a modified drag correlation with an increased $P_{S}$ value, derived by Parker, improved the correlation of the data.

Ma et al. [17] used the EMMS drag model to simulate a high-density CFB. The predicted pressure distribution deviated from experimental data in dense regions of the riser, while the particle circulation rate was predicted with relative errors less than $10 \%$.

Kraft et al. [18] simulated a dual fluidized bed with EMMS, Ganser, TurtonLevenspiel, and WYE drag laws. The EMMS drag law predicted the pressure distribution best, while the others underestimated the pressure at the bottom. The best particle circulation rates were achieved with the Ganser drag law, while EMMS's were notable lower.

Based on the literature review the EMMS, Ganser, and WYE drag laws have been tested. Generally spoken the WYE and Ganser drag law cover both dense and dilute flow but seem to overpredict the drag force in some cases. The EMMS had a promising performance, predicted the pressure distribution well, but underpredicted the particle circulation rate in some cases.

\subsection{Governing equations}

\subsubsection{Equation for fluid phase}

Continuity equation for the fluid without mass transport [19]:

$$
\frac{\partial\left(\varepsilon_{f} \rho_{f}\right)}{\partial t}+\nabla \cdot\left(\varepsilon_{f} \rho_{f} \boldsymbol{u}_{f}\right)=\delta \dot{m}_{p}=0
$$

Eq. 1: Continuity equation

where $\varepsilon_{f}$ is the fluid volume fraction, $\rho_{f}$ is the fluid density, $\boldsymbol{u}_{f}$ the fluid velocity, and $\delta \dot{m}_{p}$ the gas mass production rate per volume from particle-gas chemistry. Momentum equation for the fluid with interphase momentum transfer function $\boldsymbol{F}$ [19]:

$$
\begin{aligned}
& \frac{\partial\left(\varepsilon_{f} \rho_{f} \boldsymbol{u}_{f}\right)}{\partial t}+\nabla \cdot\left(\varepsilon_{f} \rho_{f} \boldsymbol{u}_{f} \boldsymbol{u}_{f}\right) \\
& =-\nabla p+\boldsymbol{F}+\varepsilon_{f} \rho_{f} \boldsymbol{g}+\nabla \cdot\left(\varepsilon_{f} \boldsymbol{\tau}_{f}\right)
\end{aligned}
$$

Eq. 2: Momentum equation

where $p$ is the pressure, $\boldsymbol{g}$ the gravitational acceleration, and with the fluid stress tensor in index notation [19]:

$$
\tau_{f, i j}=\mu\left(\frac{\partial u_{f, i}}{\partial x_{j}}+\frac{\partial u_{f, j}}{\partial x_{i}}\right)-\frac{2}{3} \mu \delta_{i j} \frac{\partial u_{f, k}}{\partial x_{f, k}}
$$

Eq. 3: Stress tensor

where $\mu$ is the sum of laminar shear and turbulence viscosity, $\delta_{i j}$ is the Kronecker delta, $u_{f, i}$ the fluid's velocity, and $x_{i}$ is the spatial variable.

\subsubsection{Equations for particulate phase}

The particle acceleration $\boldsymbol{a}_{p}$, as described in Eq. 4, was extended with an additional term, the modified acceleration due to contact stress. The particle acceleration is calculated using a blended particle acceleration model developed by O'Rourke and Snider [20].

$$
\begin{gathered}
\boldsymbol{a}_{p}=D\left(\boldsymbol{u}_{f}-\boldsymbol{u}_{p}\right)-\frac{1}{\rho_{p}} \nabla p+\boldsymbol{g} \\
-\frac{1}{\varepsilon_{p} \rho_{p}} \nabla \tau_{p}+\frac{\overline{\boldsymbol{u}}_{p}-\boldsymbol{u}_{p}}{2 * \tau_{D}}
\end{gathered}
$$

Eq. 4: Particle acceleration

$\overline{\boldsymbol{u}}_{p}$ is the particle mean velocity, the particle density $\rho_{p}$, and $\tau_{D}$ is a damping time due to inelastic particle collisions (see [20]).

The particle normal stress, $\tau_{\mathrm{p}}$, models the particle-particle interactions and is important near close-pack and has little effect elsewhere [21].

$$
\tau_{p}=\frac{P_{S} * \varepsilon_{p}^{\beta}}{\max \left[\varepsilon_{c p}-\varepsilon_{p}, \alpha\left(1-\varepsilon_{p}\right)\right]}
$$

Eq. 5: Particle normal stress

$\varepsilon_{p}$ is the particle volume fraction, $\varepsilon_{c p}$ is the close-pack particle volume fraction, and $P_{S}$ is a constant with the unit $\mathrm{Pa}$. The constants 
$\alpha$, a small number to avoid dividing by zero, and $\beta$ are dimensionless.

The MP-PIC method used in Barracuda describes the dynamics of the particle phase using the particle probability distribution function $f\left(x, u_{p}, \rho_{p}, V_{p}, t\right)$ and the evolution of the particle phase is determined by solving the Liouville equation for $f$ [22]:

$$
\frac{\partial f}{\partial t}+\nabla \cdot\left(f \boldsymbol{u}_{p}\right) \nabla_{\boldsymbol{u}_{p}} \cdot\left(f \boldsymbol{a}_{\boldsymbol{p}}\right)=0
$$

Eq. 6: Liouville equation for $f$

where $\nabla_{\boldsymbol{u}_{p}}$ is the divergence operator with respect to particle velocity.

The particle volume fraction is related to $f$ by [22]:

$$
\varepsilon_{p}=\iint f \frac{m_{p}}{\rho_{p}} d m_{p} d \boldsymbol{u}_{p}
$$

Eq. 7: Particle volume fraction

The interphase momentum transfer function per volume is defined as [22]:

$$
\begin{aligned}
\boldsymbol{F}=-\iint f\left(m_{p}[\right. & D\left(\boldsymbol{u}_{f}-\boldsymbol{u}_{p}\right) \\
& \left.\left.-\frac{\nabla p}{\rho_{p}}\right]\right) d m_{p} d \boldsymbol{u}_{p}
\end{aligned}
$$

Eq. 8: Interphase momentum transfer

where $D$ is the drag function.

\subsection{Drag laws}

In this paper the EMMS, Ganser, and WYE drag laws were used. All of those drag laws are already implemented and available in Barracuda. The EMMS drag law is based on an energy-minimization multi-scale approach and the drag coefficient is calculated from structure parameters of the gas solid interactions. For further information it is referred to Yang et al. [23]. The Ganser drag law is based on studies of Chhabra et al. [24] and Wen and Yu [25]. In this work the sphericity of the particles is 1 . The WYE drag law was introduced by Gidaspow [26] and is a blend of the Wen and
Yu drag law, which is appropriate for more dilute systems and the Ergun equation [27], which is appropriate at higher packing fractions. For the formulas implemented in Barracuda for the drag laws it is referred to the Barracuda Virtual Reactor version 17.3.0 user manual [28] which can also be found in [29].

\section{Concept and methodology}

The simulations were based on an existing cold flow model located at TU Wien. Martinovic [30] conducted cold flow experiments on this model. Those results were used to verify and rate the performance of the simulation. A 3D model of the cold flow model was designed in Autodesk Inventor Professional 2018, as depicted in Fig. 1, and used for this work. The model has a total height of $1.57 \mathrm{~m}$.

The main parts of the model are the air reactor (AR) column, the fuel reactor (FR) column, with four built-ins to narrow the cross-section, the FR bubbling bed (FR BB), a separator on top of the AR (AR SEP) and one on top of the FR column (FR SEP), and a total of three loop seals (Upper (ULS), Inner (ILS), and Lower loop seal (LLS)), which connect the separators with the AR and FR column respectively and the columns with each other.
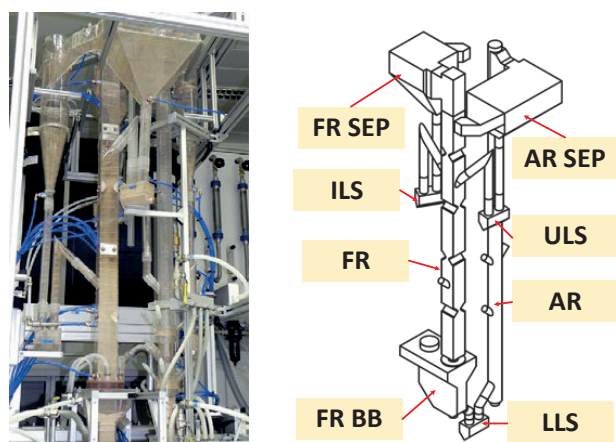

Fig. 1: Cold flow model (left) [30], 3D model for simulation (right)

The diameter of the AR was $52 \mathrm{~mm}$, the width of the square FR column $62 \mathrm{~mm}$ and $16 \mathrm{~mm}$ at the narrowing (as depicted in Fig. $1)$. 
For the cold flow model investigations bronze particles as bed material and air as fluidization agent were used. During operation the bronze particles were carried up in the riser, separated from the fluid in the separator by gravity and transported through a loop seal into the FR column. Most of the particles traveled downwards, while forming smaller fluidized beds, to the FR bubbling bed. The upwards moving particles were recirculated over a separator and a loop seal to the FR column. In the bubbling bed the particles traveled through a loop seal back to the riser.

For the simulation several settings were tested in order to accurately predict the particle behavior in the cold flow model. A focus was put on the drag law, the particle normal stress properties and influence of the fluidization rate.

The best set-up was determined in a step-bystep approach.

The simulations were conducted using Barracuda VR version 17. The hardware infrastructure was a workstation with an Intel Core i5-3570, 16 GB RAM, and a GeForce TITAN X graphics card.

\subsection{General settings}

The general settings for the simulation are listed in Tab. 1. The PSD of the particles is depicted in Fig. 2.

\begin{tabular}{|r|c|}
\hline Real cell number & 483338 \\
\hline $\begin{array}{r}\text { Total number of } \\
\text { particles }\end{array}$ & $\sim 1.16^{*} 10^{10}$ \\
\hline $\begin{array}{r}\text { Number of } \\
\text { numerical particles }\end{array}$ & $\sim 2.19^{*} 10^{6}$ \\
\hline Particle density [30] & $8800 \mathrm{~kg} / \mathrm{m}^{3}$ \\
\hline Bulk density [30] & $5100 \mathrm{~kg} / \mathrm{m}^{3}$ \\
\hline Drag law & $\begin{array}{c}\text { EMMS, WYE, } \\
\text { Ganser }\end{array}$ \\
\hline$P_{S}$ & $\begin{array}{c}1 \text { Pa (default), } \\
\text { up to } 100 \mathrm{~Pa}\end{array}$ \\
\hline Turbulence model & LES \\
\hline
\end{tabular}

Tab. 1: General settings overview

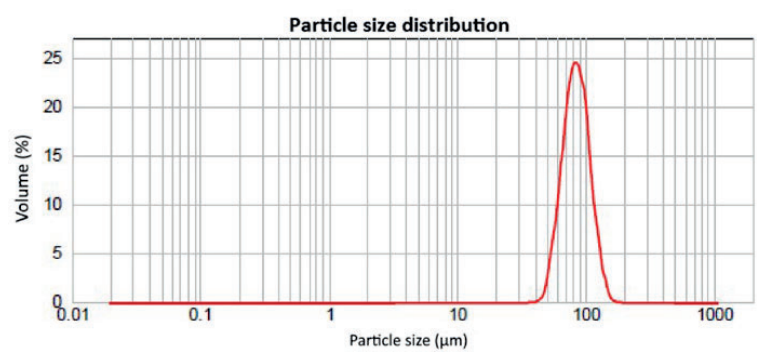

Fig. 2: Particle size distribution (PSD) of particles with a Sauter diameter of $81.7 \mu \mathrm{m} \mathrm{[30]}$

\subsection{Boundary conditions}

In order to simulate a fluidizing bed, air had to be introduced and removed from the system. The air was able to exit the model at the pressure boundary conditions and was introduced into the system at the flow boundary conditions (see Fig. 3).

At each separator a pressure boundary condition with 1 atm was defined, permeable for air but not for particles.

In each loop seal one flow boundary condition, in the $\mathrm{AR}$ four ( $\mathrm{AR} 1_{\text {lower, }}$ $\mathrm{AR} 1_{\text {upper, }} \mathrm{AR} 2_{\text {lower, }} \mathrm{AR} 2_{\text {upper }}$ ) and in the bubbling bed of the FR two flow boundary conditions (FR1 and FR2) were defined. The flow boundary conditions were set as injection points ("jets") split up in several individual flow boundary conditions. The boundary conditions in the loop seal consisted of 4 jets each, the conditions in the FR of 5 each, the conditions in the AR of 8 each. Therefore, a total of 54 active flow boundary conditions were used in the simulation to inject air into the system.

The mass flow into the system was regularly set to $24 \mathrm{Nm}^{3} / \mathrm{h}$ into the $\mathrm{AR}, 12 \mathrm{Nm}^{3} / \mathrm{h}$ into the FR, and 0.6 to $0.8 \mathrm{Nm}^{3} / \mathrm{h}$ in each loop seal (see Tab. 2). This mass flow was split up equally between the jets. An overview of the flow boundary conditions is given in Tab. 2.

Furthermore, the fluidization rate was altered in the loop seals in certain simulations to investigate its influence. 


\begin{tabular}{|l|c|c|c|}
\hline & $\begin{array}{c}\text { No. } \\
\text { of } \\
\text { jets }\end{array}$ & $\begin{array}{c}\text { Position/ } \\
\text { Height } \\
{[\mathrm{mm}]}\end{array}$ & $\begin{array}{c}\text { Vol. } \\
\text { flow } \\
{\left[\mathrm{Nm}^{3} / \mathrm{h}\right]}\end{array}$ \\
\hline FR1 & 5 & 889 & 2 \\
\hline FR2 & 5 & 1999 & 10 \\
\hline $\mathrm{AR} 1_{\text {lower }}$ & 8 & 111 & 3.69 \\
\hline $\mathrm{AR} 1_{\text {upper }}$ & 8 & 326 & 8.31 \\
\hline $\mathrm{AR} 2_{\text {lower }}$ & 8 & 425 & 8.31 \\
\hline $\mathrm{AR} 2_{\text {upper }}$ & 8 & 601 & 3.69 \\
\hline $\mathrm{LLS}$ & 4 & 11 & 0.8 \\
\hline $\mathrm{ULS}$ & 4 & 1045 & 0.8 \\
\hline $\mathrm{ILS}$ & 4 & 1045 & 0.6 \\
\hline
\end{tabular}

Tab. 2: Flow conditions overview

\subsection{Pressure measurement}

The pressure was measured over time to evaluate the pressure profile, therefore, a total of 25 pressure measurement points were defined in the FR, AR, and LLS.

\subsection{Evaluation}

The performance of the simulation was rated qualitatively, by visual observation of the rendered animation of the simulation and the generated graphs (see Fig. 3). The performance was quantitatively rated based on the mass flow rate and the pressure profile including defined parameters. The defined parameters were the pressure profile parameter $\left(\mathrm{P}_{\mathrm{PP}}\right)$ and the pressure gradient parameter $\left(\mathrm{P}_{\mathrm{PG}}\right)$.

The $\mathrm{P}_{\mathrm{PP}}$ value was defined as the pressure difference measured in the experiment and the simulation at the bottom of the FR column, which indicated the total amount of particles in the FR column. Therefore, the target value for $P_{P P}$ ist zero.

$$
P_{P P}=p_{\text {Simulation }}-p_{\text {Experiment }}
$$

Eq. 9: Pressure profile parameter

The $P_{P G}$ value was calculated by adding up the squared difference, between measured and simulated values, of the pressure gradient values in the FR column. Therefore, the target value for $P_{P G}$ is zero and it indicated the quality of the distribution in the FR column.

$$
\begin{aligned}
P_{P G}=\sum_{i}\left(\mid p^{\prime}\left(H_{i}\right)_{\text {Simulation }}\right. & \\
& \left.-\left.p^{\prime}\left(H_{i}\right)_{\text {Experiment }}\right|^{2}\right)
\end{aligned}
$$

Eq. 10: Pressure gradient parameter

The circulation rate of the particles was measured with the mass flow of the particles in the AR column. If the simulation is in a steady state and no flooding occurred, this value will reflect the circulation rate of the particles. The measured value on the cold flow model in experiments was $823 \mathrm{~kg} / \mathrm{h}$ (marked as a dashed line in Fig. 4, Fig. 5, and Fig. 6) with an AR fluidization rate of 24 $\mathrm{Nm}^{3} / \mathrm{h}$.

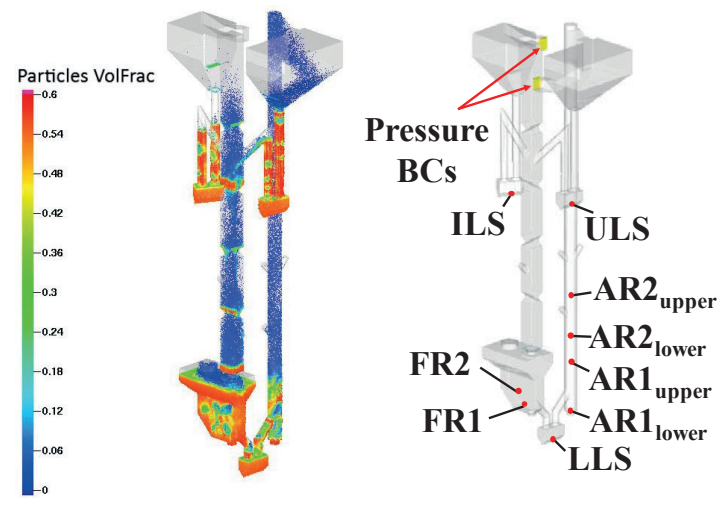

Fig. 3: Visualization of the CPFD simulation (left), boundary conditions (BCs) for simulation (right) 


\section{Results and discussion}

Overview of simulations

\begin{tabular}{|c|c|c|c|c|c|}
\hline $\begin{array}{l}\text { Abbre- } \\
\text { viation }\end{array}$ & Drag Law & Mesh & $\begin{array}{c}\mathrm{PS} \\
{[\mathrm{Pa}]}\end{array}$ & $\begin{array}{l}\text { LLS Fluidization } \\
\text { rate }\left[\mathrm{Nm}^{3} / \mathrm{h}\right]\end{array}$ & $\begin{array}{l}\text { AR Fluidization } \\
\text { rate }\left[\mathrm{Nm}^{3} / \mathrm{h}\right]\end{array}$ \\
\hline E300 & EMMS & $300 \mathrm{k}$ & 1 & 0.8 & 24 \\
\hline G300 & WYE & $300 \mathrm{k}$ & 1 & 0.8 & 24 \\
\hline W300 & WYE & $300 \mathrm{k}$ & 1 & 0.8 & 24 \\
\hline G500 & Ganser & $500 \mathrm{k}$ & 1 & 0.8 & 24 \\
\hline W500 & WYE & $500 \mathrm{k}$ & 1 & 0.8 & 24 \\
\hline PS1 & Ganser & $500 \mathrm{k}$ & 1 & 0.8 & 24 \\
\hline PS30 & Ganser & $500 \mathrm{k}$ & 30 & 0.8 & 24 \\
\hline PS50 & Ganser & $500 \mathrm{k}$ & 50 & 0.8 & 24 \\
\hline PS65 & Ganser & $500 \mathrm{k}$ & 65 & 0.8 & 24 \\
\hline PS100 & Ganser & $500 \mathrm{k}$ & 100 & 0.8 & 24 \\
\hline G1n & Ganser & $500 \mathrm{k}$ & 1 & 0.8 & 24 \\
\hline G1a & Ganser & $500 \mathrm{k}$ & 1 & 1.4 & 24 \\
\hline G30n & Ganser & $500 \mathrm{k}$ & 30 & 0.8 & 24 \\
\hline G30a & Ganser & $500 \mathrm{k}$ & 30 & 1.4 & 24 \\
\hline G30b & Ganser & $500 \mathrm{k}$ & 30 & 2 & 24 \\
\hline W1n & WYE & $500 \mathrm{k}$ & 1 & 0.8 & 24 \\
\hline W30n & WYE & $500 \mathrm{k}$ & 30 & 0.8 & 24 \\
\hline W30a & WYE & $500 \mathrm{k}$ & 30 & 1.4 & 24 \\
\hline E30n & EMMS & $500 \mathrm{k}$ & 30 & 0.8 & 24 \\
\hline E30a & EMMS & $500 \mathrm{k}$ & 30 & 1.4 & 24 \\
\hline $16 \mathrm{a}$ & Ganser & $500 \mathrm{k}$ & 30 & 1.4 & 16 \\
\hline $16 \mathrm{~b}$ & Ganser & $500 \mathrm{k}$ & 50 & 0.8 & 16 \\
\hline $20 \mathrm{a}$ & Ganser & $500 \mathrm{k}$ & 30 & 1.4 & 20 \\
\hline $20 \mathrm{~b}$ & Ganser & $500 \mathrm{k}$ & 50 & 0.8 & 20 \\
\hline $24 a$ & Ganser & $500 \mathrm{k}$ & 30 & 1.4 & 24 \\
\hline $24 b$ & Ganser & $500 \mathrm{k}$ & 50 & 0.8 & 24 \\
\hline
\end{tabular}

Tab. 3: Overview of simulations

\section{Drag law pre-selection}

In order to find a suitable drag law for the simulation the three drag laws: Ganser, WYE, and EMMS were tested. First simulations were conducted with a coarser grid, with about 300000 ("300k") cells (Fig. 4: "E300", "W300", "G300”), to investigate the general trend of the drag laws. Subsequent simulations were conducted as described previously with a mesh with approximately 500000 ("500k") cells (Fig. 4: "G500" and "W500"). The defined parameters in Fig. 4 show a similar performance of both the Ganser and WYE drag laws, but with both drag laws and chosen settings flooding of the AR SEP was observed in the rendered animation. The AR SEP flooding occurred slower with the
Ganser drag law compared to the WYE drag law in the simulation with $500 \mathrm{k}$ cells.

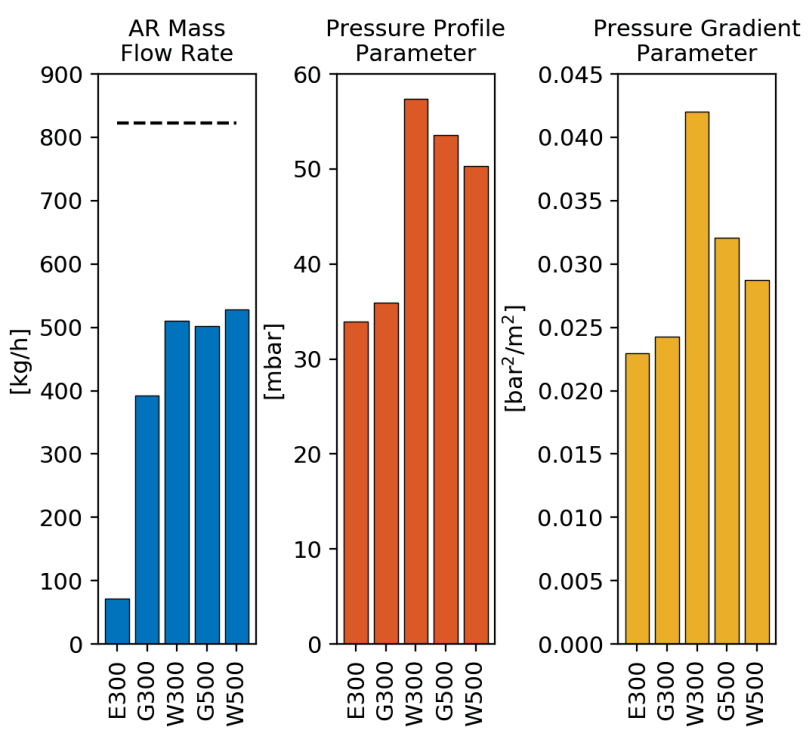

Fig. 4: Drag law variation with 300k and 500k cells 
The other parameters, $P_{S}$ and LLS fluidization rate, were tested with all three drag laws to find the best settings. In general, the EMMS drag law did perform worse compared to the other drag laws. An explanation for those results could be found by looking at the conditions on which the implemented EMMS model ("EMMSYang-2004 model") in Barracuda was based on. Among other conditions, the model was generated for a particle density of $930 \mathrm{~kg} / \mathrm{m}^{3}$ and a solid flux of $14.3 \mathrm{~kg} / \mathrm{m}^{2} \mathrm{~s}$. The particle density of the bronze particles is $8800 \mathrm{~kg} / \mathrm{m}^{3}$ and considering a diameter in the AR column of $52 \mathrm{~mm}$, the mass flux is approx. $107 \mathrm{~kg} / \mathrm{m}^{2} \mathrm{~s}$.

\section{$P_{S}$ variation}

In first simulations of the cold flow model it was observed from graphs and rendered animations, that the pressure drop and bed's height building up in the FR column are significantly higher than the measured values of the cold flow experiments. Additionally, it was a high particle volume fraction close to close-pack observed in the simulation. In order to reduce the number of particles in the FR column the $P_{S}$ value was varied to influence the particle normal stress and particle acceleration (see Eq. 4). The $\mathrm{P}_{\mathrm{S}}$ value variation was conducted from $1 \mathrm{~Pa}$ (default) to $100 \mathrm{~Pa}$ with the Ganser drag law. The simulation results are shown in Fig. 5.
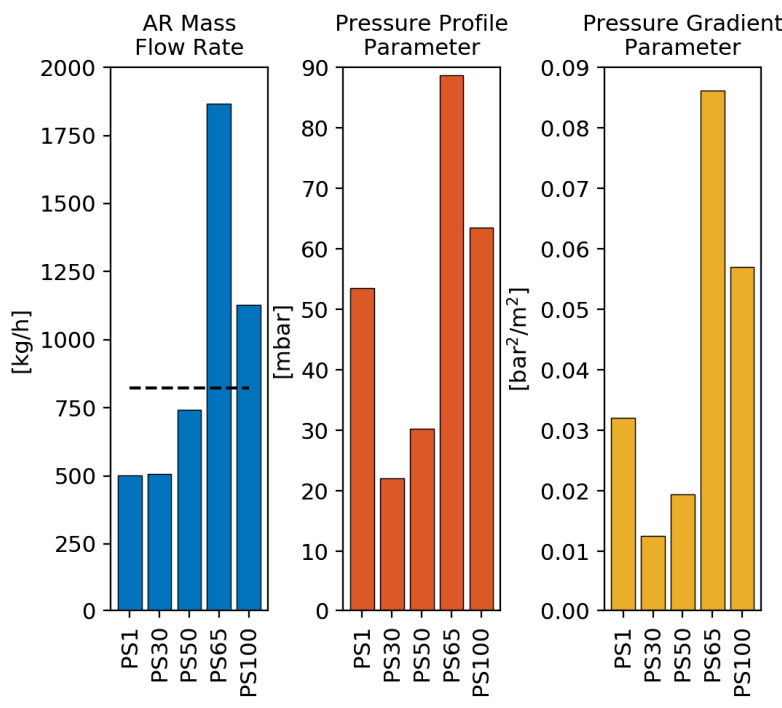

Fig. 5: $P_{S}$ constant variation with Ganser
The increased $\mathrm{P}_{\mathrm{S}}$ value to 30 and $50 \mathrm{~Pa}$ improved the pressure drop and pressure gradient in the FR column (see Fig. 5) while improving the particle circulation rate.

Loop seal fluidization rate variation and different drag laws

The influence of the LLS fluidization rate on particle circulation rate was observed and if the LLS fluidization rate is limiting the particle circulation rate. If the LLS limits the particle circulation a small error would impact the whole simulation on the one hand. On the other hand, adjustments to the LLS fluidization rate would allow more realistic results by adjusting the model and knowing this possible error.

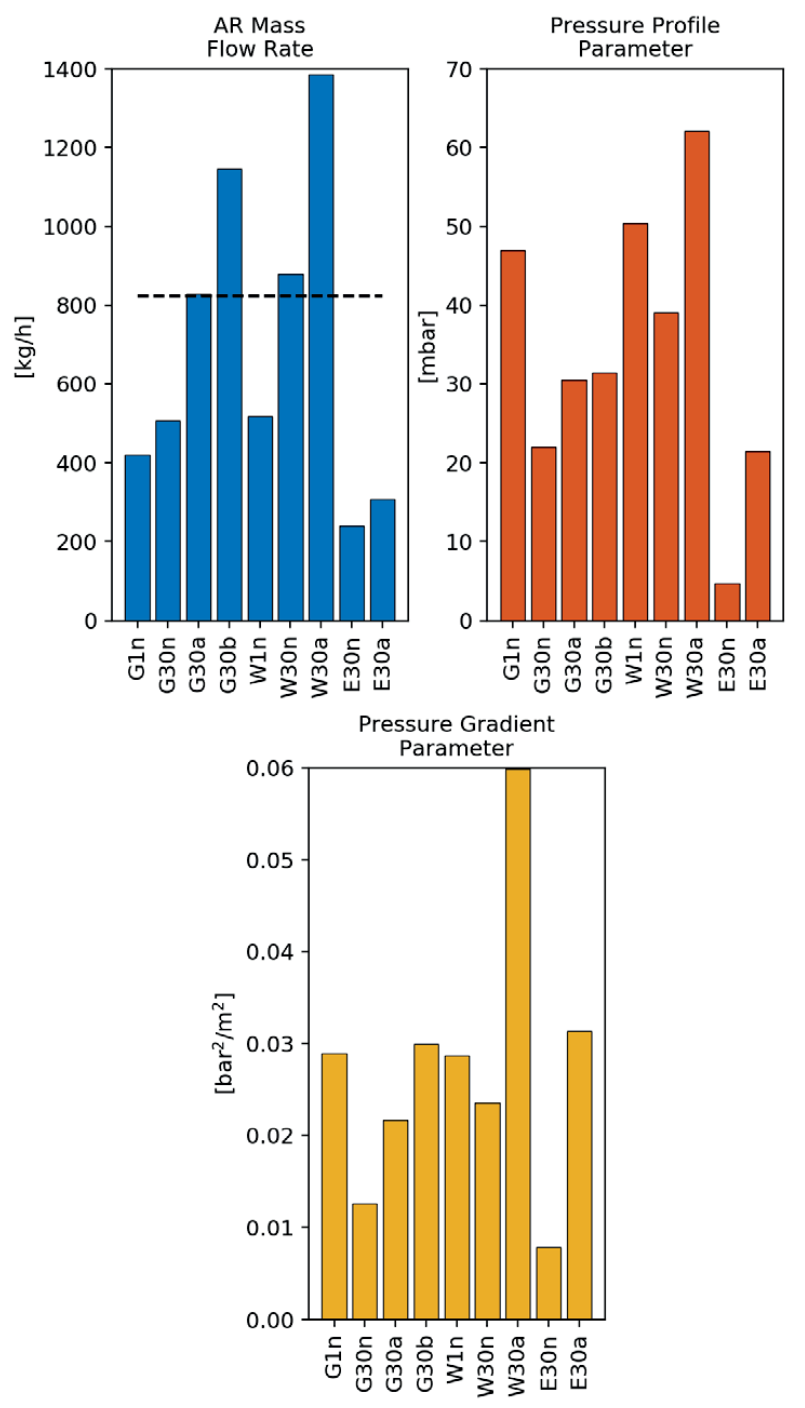

Fig. 6: Variation of loop seal fluidization rate Simulations with non-increased loop seal fluidization rates are labeled as "n", increased by the factor 1.75 as "a", and increased by the factor 2.5 as "b" 
The simulations with Ganser and an adjusted $\mathrm{P}_{\mathrm{S}}$ value to $30 \mathrm{~Pa}$ reached a stable steady state (Fig. 6). They improved further with 1.75 times increased loop seal fluidization rates. The WYE drag law predicted an AR mass flow larger than the ULS mass flow rate in all tested cases, which led to flooding of the AR SEP and an unsteady state. The EMMS drag law underestimated the mass flows with all adjustments. Those trends reflected the behavior observed previously during drag law variation. Therefore, Ganser had the best performance for the simulations. The WYE and EMMS drag laws were tested further.

\section{Different operating points}

Different operating points of the cold flow model were tested, with set AR fluidization rates from 16 to $24 \mathrm{Nm}^{3} / \mathrm{h}$. The results are visualized in Fig. 7 and Fig. 8. The operating points were simulated with $\mathrm{P}_{\mathrm{S}}=30 \mathrm{~Pa}$ and altered loop seal fluidization rates, which are labeled with "a", and with $\mathrm{P}_{\mathrm{S}}=50$ and nonaltered loop seal fluidization rates which are labeled as "b". The AR fluidization rate is indicated by the prefixed number in Fig. 7.

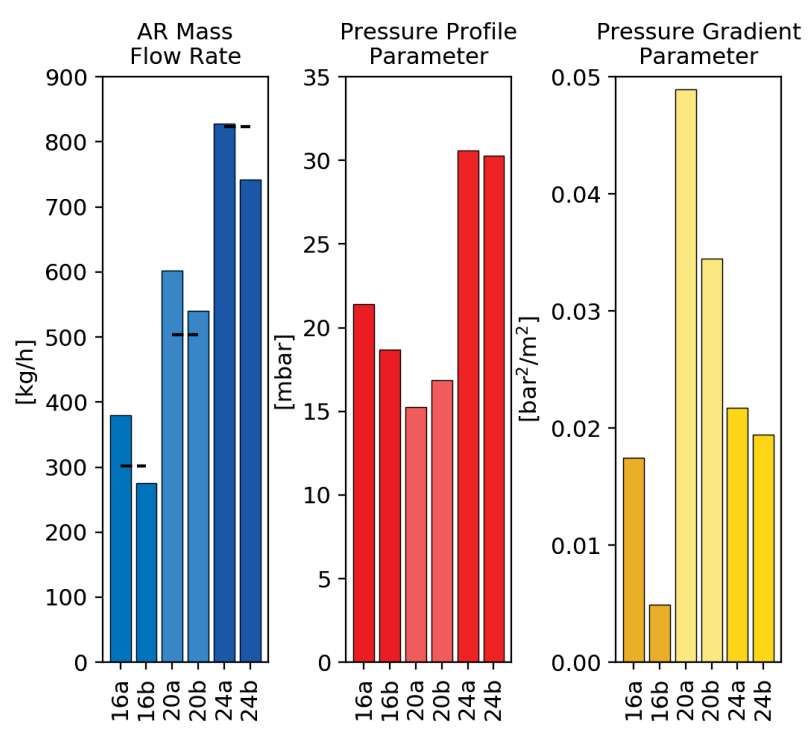

Fig. 7: Simulations of different operating point Simulations with altered loop seal fluidization rates and $P_{S}=30 \mathrm{~Pa}$ are labeled as "a", with non-altered loop seal fluidization rates and $P_{S}=50 \mathrm{~Pa}$ are labeled as "b"

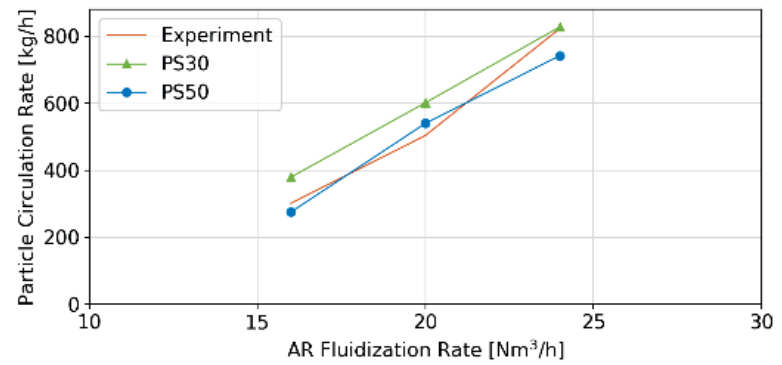

Fig. 8: Particle circulation rates at different operating points

The simulations with altered loop seal fluidization rates and $\mathrm{P}_{\mathrm{S}}$ of $30 \mathrm{~Pa}$ predicted larger mass flow rates compared to the cases with normal loop seal fluidization rates and $\mathrm{P}_{\mathrm{S}}$ of $50 \mathrm{~Pa}$. The pressure difference over the FR column is in both cases very similar. The biggest was observed in particle distribution in the FR column represented as the pressure gradient. The pressure gradient deviation ( $P_{P G}$ value) visualized in Fig. 7 reflects the observation, that the cases with $\mathrm{P}_{\mathrm{S}}$ set to 50 $\mathrm{Pa}$ are predicting the real particle distribution of the cold flow model better.

Subsequently, the settings with $\mathrm{P}_{\mathrm{S}}$ of $30 \mathrm{~Pa}$ and increased loop seal fluidization rates will be referred to as case "A", the settings with $\mathrm{P}_{\mathrm{S}}$ of $50 \mathrm{~Pa}$ and normal loop seal fluidization rates will be referred to as case "B". The particle circulations rates of the simulation compared to the measured experimental circulation rates by Martinovic [30] are depicted in Fig. 8. The simulation with an AR fluidization rate of $16 \mathrm{Nm}^{3} / \mathrm{h}$ overpredicted the particle circulation rate (302 $\mathrm{kg} / \mathrm{h})$ in case A by $26 \%$ and underpredicted in case $\mathrm{B}$ by $9 \%$. The simulation with an AR fluidization rate of 20 $\mathrm{Nm}^{3} / \mathrm{h}$ overpredicted the particle circulation rate $(504 \mathrm{~kg} / \mathrm{h})$ in case $\mathrm{A}$ by $19 \%$ and overpredicted in case $\mathrm{B}$ by $7 \%$. The simulation with an AR fluidization rate of 24 $\mathrm{Nm}^{3} / \mathrm{h}$ overpredicted the particle circulation rate $(823 \mathrm{~kg} / \mathrm{h})$ in case $\mathrm{A}$ by $1 \%$ and underpredicted in case B by $10 \%$. 
Overall the simulation with $\mathrm{P}_{\mathrm{S}}$ set to $50 \mathrm{~Pa}$ and regular loop seal fluidization had a better performance due to the pressure parameters and sufficient mass flow rates. The simulations with $\mathrm{P}_{\mathrm{S}}$ set to $30 \mathrm{~Pa}$ and increased loop seal fluidization rates tended to overpredict the mass flow rates and accumulated too many particles in the upper part of the FR column. The dependence of the particle circulation rate from the AR fluidization rate of the real case and the simulated cases is depicted in Fig. 8. Latter shows the clear trend of increasing particle circulation rates with increased $A R$ fluidization rates. Based on those investigations, the best results on various operating points are calculated with a $\mathrm{P}_{\mathrm{S}}$ value of $50 \mathrm{~Pa}$.

\section{Conclusion and outlook}

The most important settings for the simulation are the drag law and the $\mathrm{P}_{\mathrm{S}}$ constant. In particular the $P_{S}$ constant played a significant role to achieve a steady state behavior, reduce bed heights in the FR column, and to achieve realistic particle circulation rates. The Ganser drag law and a $\mathrm{P}_{\mathrm{S}}$ value of $50 \mathrm{~Pa}$ led to the best results overall. The loop seal fluidization rate had also a significant influence. Comparable results were achieved with a $P_{S}$ value of 30 $\mathrm{Pa}$ and increased loop seal fluidization by 1.75, which led to a worse particle distribution but to a similar particle circulation rate. Different operating points were successfully simulated with those settings.

The ideal $P_{S}$ value could be further investigated by repeating the simulation with slightly varied $\mathrm{P}_{\mathrm{S}}$ values. Although good results were achieved by only adjusting the $\mathrm{P}_{\mathrm{S}}$ value the variation of the $\beta$ constant could further improve the simulation and should be considered in future simulations. In the next stage the settings of the cold flow model could be used to simulate a pilot plant. After simulating the cold flow operation of a pilot plant successfully, heat transfer and chemical reactions should be modeled and implemented. A reliable and robust CFD model allows faster and cost-effective testing. Different set-ups of the actual gasification plant can be tested without physical modifications to optimize the geometry. Furthermore, a computational simulation allows deeper insight into the plant itself and is not limited by sight or measuring points. Therefore, fluid dynamical behavior can be investigated at any desired location. This could lead to faster implementation of the technology and improved quality of the product gas with a reduced tar content. 


\section{List of abbreviations}

\begin{tabular}{|l|l|}
\hline abbreviation & \multicolumn{1}{|c|}{ meaning } \\
\hline AR & air reactor \\
\hline BB & bubbling bed \\
\hline BCs & boundary conditions \\
\hline CFB & $\begin{array}{l}\text { compulating fluidized bed } \\
\text { dynamics }\end{array}$ \\
\hline CFD & $\begin{array}{l}\text { computational particle } \\
\text { fluid dynamics }\end{array}$ \\
\hline CPFD & dual fluidized bed \\
\hline DFB & exempli gratia \\
\hline e.g. & et cetera \\
\hline etc. & $\begin{array}{l}\text { energy-minimization } \\
\text { multi- scale (EMMS } \\
\text { drag model) }\end{array}$ \\
\hline EMMS & equation \\
\hline Eq. & fuel reactor \\
\hline FR & initial condition \\
\hline IC & inner loop seal \\
\hline ILS & large eddy simulation \\
\hline LES & lower loop seal \\
\hline LLS & $\begin{array}{l}\text { multi phase particle in } \\
\text { cell }\end{array}$ \\
\hline MP-PIC & particle size distribution \\
\hline PSD & separator \\
\hline SEP & $\begin{array}{l}\text { Wen-Yu and Ergun } \\
\text { (WYE drag model) }\end{array}$ \\
\hline ULS & \\
\hline WYE & \\
\hline
\end{tabular}

\begin{tabular}{|c|c|c|}
\hline symbol & meaning & $\begin{array}{c}\text { SI } \\
\text { unit }\end{array}$ \\
\hline $\boldsymbol{a}_{p}$ & $\begin{array}{l}\text { particle } \\
\text { acceleration }\end{array}$ & $m / s^{2}$ \\
\hline$D$ & drag function & $1 / s$ \\
\hline $\boldsymbol{F}$ & $\begin{array}{l}\text { interphase } \\
\text { momentum } \\
\text { transfer function }\end{array}$ & $N / m^{3}$ \\
\hline$p$ & pressure & $P a$ \\
\hline$g$ & $\begin{array}{l}\text { gravitational } \\
\text { acceleration }\end{array}$ & $m / s^{2}$ \\
\hline$t$ & time & $S$ \\
\hline$P_{S}$ & $\begin{array}{l}\text { constant to } \\
\text { calculate } \tau_{p}\end{array}$ & $P a$ \\
\hline $\boldsymbol{u}_{f}$ & fluid velocity & $m / s$ \\
\hline$u_{p}$ & particle velocity & $m / s$ \\
\hline$\overline{\boldsymbol{u}}_{p}$ & $\begin{array}{l}\text { particle mean } \\
\text { velocity }\end{array}$ & $m / s$ \\
\hline$x_{i}$ & spatial variable & $m$ \\
\hline$\alpha$ & $\begin{array}{l}\text { constant to } \\
\text { calculate } \tau_{p}\end{array}$ & - \\
\hline$\beta$ & $\begin{array}{l}\text { constant to } \\
\text { calculate } \tau_{p}\end{array}$ & - \\
\hline$\varepsilon_{c p}$ & $\begin{array}{l}\text { close-pack } \\
\text { particle volume } \\
\text { fraction }\end{array}$ & - \\
\hline$\varepsilon_{f}$ & $\begin{array}{l}\text { fluid volume } \\
\text { fraction }\end{array}$ & - \\
\hline$\varepsilon_{p}$ & $\begin{array}{l}\text { particle volume } \\
\text { fraction }\end{array}$ & - \\
\hline$\delta_{i j}$ & Kronecker delta & - \\
\hline$m_{p}$ & particle mass & $k g$ \\
\hline$\mu$ & viscosity & $\mathrm{kg} / \mathrm{m} * \mathrm{~s}$ \\
\hline$\nabla$ & nabla operator & $1 / m$ \\
\hline$\rho_{f}$ & fluid density & $\mathrm{kg} / \mathrm{m}^{3}$ \\
\hline$\tau_{D}$ & $\begin{array}{l}\text { damping time due } \\
\text { to inelastic } \\
\text { particle collisions }\end{array}$ & $S$ \\
\hline$\tau_{f}$ & fluid stress tensor & $N / m^{2}$ \\
\hline$\tau_{p}$ & $\begin{array}{l}\text { particle normal } \\
\text { stress }\end{array}$ & $N / m^{2}$ \\
\hline
\end{tabular}




\section{References}

[1] J. Schmid, "Development of a novel dual fluidized bed gasification system for increased fuel flexibility," TU Wien, Dr. thesis, 2014.

[2] M. Kuba, S. Kraft, F. Kirnbauer, F. Maierhans, and H. Hofbauer, "Influence of controlled handling of solid inorganic materials and design changes on the product gas quality in dual fluid bed gasification of woody biomass," Appl. Energy, vol. 210, pp. 230-240, 2018.

[3] F. Fotovat, A. Abbasi, R. J. Spiteri, H. de Lasa, and J. Chaouki, "A CPFD model for a bubbly biomass-sand fluidized bed," Powder Technol., vol. 275, pp. 39-50, 2015.

[4] Y. Liang, Y. Zhang, T. Li, and C. Lu, "A critical validation study on CPFD model in simulating gas-solid bubbling fluidized beds," Powder Technol., vol. 263, pp. 121-134, 2014.

[5] J. M. Weber, K. J. Layfield, D. T. Van Essendelft, and J. S. Mei, "Fluid bed characterization using electrical capacitance volume tomography (ECVT), compared to CPFD software's barracuda," Powder Technol., vol. 250, pp. 138-146, 2013.

[6] L. Zhang, Z. Wang, Q. Wang, H. Qin, and X. Xu, "Simulation of oil shale semi-coke particle cold transportation in a spouted bed using CPFD method," Powder Technol., vol. 301, pp. 360-368, 2016.

[7] X. Shi, R. Sun, X. Lan, F. Liu, Y. Zhang, and J. Gao, "CPFD simulation of solids residence time and back-mixing in CFB risers," Powder Technol., vol. 271, pp. 16-25, 2015.

[8] X. Shi, Y. Wu, X. Lan, F. Liu, and J. Gao, "Effects of the riser exit geometries on the hydrodynamics and solids back-mixing in CFB risers: 3D simulation using CPFD approach," Powder Technol., vol. 284, pp. 130-142, 2015.

[9] S. S. Rodrigues, A. Forret, F. Montjovet, M. Lance, and T. Gauthier, "CFD modeling of riser with Group B particles," Powder Technol., vol. 283, pp. 519-529, 2015.

[10] Q. Wang et al., "Particle size distribution in CPFD modeling of gas-solid flows in a CFB riser," Particuology, 2015.

[11] X. Shi, X. Lan, F. Liu, Y. Zhang, and J. Gao, "Effect of particle size distribution on hydrodynamics and solids back-mixing in CFB risers using CPFD simulation," Powder Technol., vol. 266, pp. 135-143, 2014.

[12] C. Chen, J. Werther, S. Heinrich, H. Y. Qi, and E. U. Hartge, "CPFD simulation of circulating fluidized bed risers," Powder Technol., vol. 235, pp. 238-247, 2013.

[13] S. Clark, D. M. Snider, and J. Spenik, "CO2 adsorption loop experiment with eulerian-lagrangian simulation," Powder Technol., vol. 242, pp. 100-107, 2013.

[14] Q. Wang et al., "Application of CPFD method in the simulation of a circulating fluidized bed with a loop seal, part I-Determination of modeling parameters," Powder Technol., vol. 253, pp. 814-821, 2014.

[15] M. A. Hamilton, K. J. Whitty, and J. S. Lighty, "Numerical Simulation Comparison of Two Reactor Configurations for Chemical Looping Combustion and Chemical Looping With Oxygen Uncoupling," J. Energy Resour. Technol., vol. 138, no. 4, p. 042213, 2016.

[16] B. D. Adkins, N. Kapur, T. Dudley, S. Webb, and P. Blaser, "Experimental validation of CFD hydrodynamic models for catalytic fast pyrolysis," Powder Technol., vol. 316, pp. 725-739, 2017.

[17] Q. Ma, F. Lei, X. Xu, and Y. Xiao, "Three-dimensional full-loop simulation of a high-density CFB with standpipe aeration experiments," Powder Technol., vol. 320, pp. 574-585, 2017.

[18] S. Kraft, F. Kirnbauer, and H. Hofbauer, "Influence of drag laws on pressure and bed material recirculation rate in a cold flow model of an $8 \mathrm{MW}$ dual fluidized bed system by means of CPFD," Particuology, vol. 36, pp. 70-81, 2017.

[19] D. M. Snider, S. M. Clark, and P. J. O'Rourke, "Eulerian-Lagrangian method for three-dimensional thermal reacting flow with application to coal gasifiers," Chem. Eng. Sci., vol. 66, no. 6, pp. 1285-1295, 2011.

[20] P. J. O'Rourke and D. M. Snider, "A new blended acceleration model for the particle contact forces induced by an interstitial fluid in dense particle/fluid flows," Powder Technol., vol. 256, pp. 39-51, 2014.

[21] D. M. Snider, "An Incompressible Three-Dimensional Multiphase Particle-in-Cell Model for Dense Particle Flows," J. Comput. Phys., 2001.

[22] M. J. Andrews and P. J. O'Rourke, "The multiphase particle-in-cell (MP-PIC) method for dense particulate flows," Int. J. Multiph. Flow, vol. 22, no. 2, pp. 379-402, 1996.

[23] N. Yang, W. Wang, W. Ge, L. Wang, and J. Li, "Simulation of heterogeneous structure in a circulating fluidizedbed riser by combining the two-fluid model with the EMMS approach," Ind. Eng. Chem. Res., vol. 43, no. 18, pp. 5548-5561, 2004.

[24] R. P. Chhabra, L. Agarwal, and N. K. Sinha, "Drag on non-spherical particles: an evaluation of available methods," Powder Technol., vol. 101, no. 3, pp. 288-295, 1999.

[25] C. Y. Wen, "YH Yu. Mechanics of fluidization," in Chemical Engineering Progress Symposium Series, 1966, vol. 62, no. 62, pp. 100-111.

[26] D. Gidaspow, Multiphase flow and fluidization: continuum and kinetic theory descriptions. Academic press, 1994.

[27] S. Ergun, "Fluid flow through packed columns," Chem. Eng. Prog., vol. 48, pp. 89-94, 1952.

[28] CPFD Software LLC., "Barracuda Virtual Reactor User Manual.” 2018.

[29] S. Kraft, "Investigation of particle mixing in dual fluidized bed gasification systems by means of cold flow modelling and computational methods," PhD Thesis, TU Wien, no. August 2017, 2017.

[30] D. Martinovic, "Kaltmodellversuche und MSR-Konzept einer Zweibett-Wirbelschicht-Vergasungsanlage," Technische Universität Wien, 2013. 